\title{
Perancangan Sistem Informasi Pengingat Perbaikan Komponen Pesawat Berbasis Web
}

\author{
AlHusain ${ }^{1}$ \\ Wildan Muhtadin ${ }^{2}$ \\ Agus Supriadi ${ }^{3}$
}

\begin{abstract}
Dosen STMIK Raharja ${ }^{1}$, Mahasiswi STMIK Raharja jurusan Sistem Informasi ${ }^{2,3}$
E-mail: alhusain@ raharja.info ${ }^{1}$; wildan.muhtadin@ raharja.info ${ }^{2}$; agus.supriadi@raharja.info ${ }^{3}$
\end{abstract}

\begin{abstract}
ABSTRAK
Sebagai Pengingat (remainder) menggunakan SMS (Short Message Service) telah banyak dimanfaatkan oleh manusia. Selain memiliki jangkauan luas, hingga mencapai daerah pedesaan, SMS mudah digunakan dan efisien, SMS Gateway adalah suatu komunikasi dua arah dengan menggunakan tarif normal sesuai dengan tarif yang diberlakukan oleh operator. SMS Gateway memiliki berbagai macam jenis, Pada PT. GMF Aeroasia akan diajukan aplikasi Perancangan Sistem Informasi Pengingat Perbaikan Komponen Pesawat yang dapat membantu sistem yang sedang berjalan yaitu SAP Swift, Pada aplikasi ini, penulis memanfaatkan aplikasi SMS Gateway dengan dua fitur, yaitu SMS Pengingat (Reminder) dan SMS Autorespond. Dengan adanya SMS Pengingat, diharapkan dapat membantu para Planner (Perencana) dalam mengingatkan pembuatan Shipment Order komponen yang akan melakukan maintenance(perawatan), sedangkan melalui SMS Autorespond, Planner (Perencana) dapat melakukan pengecekan jadwal kedatangan komponen. Bahasa pemrograman yang digunakan dalam merancang aplikasi $S M S$ ini adalah PHP. Untuk penyimpanan data, penulis menggunakan $S A P$. Sementara untuk membangun aplikasi SMS, penulis menggunakan Gammu. Hasil dari aplikasi ini, Planner (Perencana) akan mendapatkan SMS pengingat sebanyak empat kali, yaitu pada hari sebelum komponen tiba di gudang yaitu dua hari dan tiga hari selama komponenberada di gudang, pada hari $\mathrm{H}$ atau tepat pada batas akhir pembuatan Shipment Order, dan hari satu hari setelah batas akhir pembuatan Shipment Orderoleh Planner (Perencana) tersebut.
\end{abstract}

Kata Kunci : SAP,SMS (Short Message Service), Gammu, SMS Gateway, SMS Reminder.

\section{ABSTRACT}

As a reminder (remainder) Using SMS (Short Message Service) has been used by humans. Besides having a wide range, to reach rural areas, easy to use and efficient SMS, SMS Gateway is a two-way communication using the normal rate in accordance with the tariffs applied by operators. SMS Gateway has various types, In. GMF will be filed applications Reminder Information System Design Aircraft Component Repair can help the running system ie SAP Swift, In this application, the authors utilize the SMS Gateway application with two features, namely SMS Reminder (Reminder) and SMS Autorespond. With the SMS Reminders, is expected to help Planner (Planning) in the Order Shipment remind manufacture components that will perform maintenance (maintenance), while via SMS Autorespond, Planners (Planner) can check the schedule of arrival of the components. The programming language used in designing the SMS application is PHP. For data storage, the authors use SAP. While to build SMS application, the author uses Gaтmu. Results from this application, Planner (Planner) will get $S M S$ reminders four times, ie on the day before the components arrive at the warehouse that is, 
two days and three days during the components are in the warehouse, on the day or right on the deadline for the manufacture of Shipment Order, and day one day after the deadline for manufacture of Shipment Order by Planner (Planner) is.

Keywords: SAP, SMS (Short Message Service), Gammu, SMS Gateway, SMS Reminder.

\section{PENDAHULUAN}

Di dalam proses maintenance (perawatan) tentunya tidak semua komponen dapat di tangani oleh GMF Aeroasia, karena itulah diadakannya kontrak kerjasama dengan Vendor (perusahaan pihak ketiga penyedia jasa maintenance (perawatan) dan change (tukar) komponen unserviceable (komponen yang tidak layak digunakan oleh pesawat dikerenakan berbagai faktor termasuk kategori perawatan dan perbaikan) dengan komponen Serviceable (komponen yang layak digunakan dan sudah melakukan perbaikan dan pengetesan).

Proses pengadan komponen yang dilakukan oleh para vendor adalah aktifitas utama pada siklus pengeluaran dan pemasukan komponen yang akan melakukan maintenance oleh GMF Aeroasia.

Siklus pengeluaran dan pemasukan komponen merupakan bagian penting dari kegiatan operasi yang dilakukan oleh GMF Aeroasia Oleh karena itu, dibutuhkan rotable control (pengontrolan rotasi keberadaan dan status komponen pesawat yang sedang digunakan maupun yang sudah tidak digunakan) dari GMF Aeroasia agar aktivitas dari siklus pengeluaran dan pemasukan komponen tersebut menjadi efektif dan efisien.

Rotable control (pengontrolan rotasi keberadaan komponen) adalah sebuah cara atau proses yang dibuat agar suatu organisasi dapat mencapai tujuannya. Salah satu model dari rotable control adalah Commitee of Sponsoring Organization of The Treadway Comission (COSO). Definisi rotable control menurut COSO adalah:

"Internal control is a process, effected by an entity's board of director, management, and other personnel, designed to provide reasonable assurance regarding the achievement of objectives in the following categories: Effectiveness and efficiency of operations; Reliability of reporting and Compliance with applicable laws and regulations."

Dari pengertian tersebut efektifitas dan efesiensi dari operasi merupakan salah satu objektif dari proses rotable control). Sistem Rotable control menurut COSO memiliki lima komponen yaitu (1) Lingkungan Pengendalian (Control Environment), (2) Penilaian Risiko (Risk Assesment), (3) Aktivitas Pengendalian (Control Activities), (4) Informasi dan Komunikasi (Information and Comunication), dan (5) Pemantauan (Monitoring). Kelima komponen tersebutlah yang akan menilai apakah rotable control di sebuah unit itu efektif dan efisien. 


\section{PERMASALAHAN}

Dalam hal ini, sistem Swift yang merupakan salah satu produk sistem SAP adalah sebuah sistem yang digunakan untuk proses bisnis di PT.GMF Aeroasia namun sistem tersebut belum mampu mendeteksi secara akurat mengenai kebaradaan fisik dari komponen yang didata pada sistem yang di masukan oleh staf yang bersangkutan, sehingga Planner selama ini hanya menunggu informasi yang akurat dari staf gudang GADC 3000 dan mendatangi langsung ke Gudang GADC 3000.

Pada akhirnya Planner akan bekerja extra dan staf gudang GADC 3000 pun melakukan hal yang sama. hal tersebut pengiriman komponen yang akan di perbaiki ke vedor dapat terganggu disebabkan waktu yang dibutuhkan tidak efisien, hal tersebut berpengaruh terhadap batas waktu pengembalian komponen uncerviceable milik vendor padahal komponen serviceable sudah diterima oleh GMF Aeroasia, karenanya GMF Aeroasia pun harus membayar late fee denda atas keterlambatan tersebut.

\section{METODOLOGI PENELITIAN}

Penelitian ini berbetuk studi kasus dengan Metode penelitian berupa metode Literature Review yang dilakukan oleh peneliti dengan cara mencari, membaca dan memahami berbagai sumber referensi yang ada seperti jurnal dan buku. Berdasarkan ini adalah beberapa Literature Review yang digunakan dalam penelitian ini:

1. Menurut Reynaldi, dkk (2017) dalam jurnal "Perancangan Sistem Administrasi Sekolah Dengan Sms Gateway Berbasis Web Menggunakan Gammu Pada SMK LPI Semarang". Penelitian ini dilakukan untuk mengetahui tingkat ketidakhadiran siswa dan keterlambatan pembayaran biaya sekolah. SMK LPI Semarang masih menggunakan metode manual (surat fisik) untuk memberikaninformasi kepada orang tua siswa yang bersangkutan. Tujuan dari penelitian ini yaitumengimplementasikan dan mengembangkanSMS Gateway berbasis web sebagai mediapelayanan informasi pada hal absensi dan pembayaran biaya sekolah. Perancangan metodeprototyping dengan model pengembangan SDLC (System Development Life Cycle) dipilih untukdigunakan sebagai penyelesaian masalah, dengan memanfaatkan diagram UML seperti usecase, sequence, dan activity diagram sebagai desain tahap awal. Pengkodean yang dilakukanpada penelitian ini adalah dengan Menggunakan Gammu sebagai aplikasi utama SMSGateway, framework PHP sebagai tampilan antarmuka, serta MySQL sebagai databasepenyimpanan. Setelah semua proses selesai, dilakukanlah pengujian terhadap setiap fungsipada aplikasi SMS Gateway berbasis web menggunakan metode black box testing. Apabila datainput yang diuji menunjukkan sesuai dengan hasil yang diharapkan, maka fungsi tersebut lolos validasi.

2. Menurut Ari (2018) dalam laporan "Implementasi Gammu Pada Sistem Pemesanan Lapangan Futsal Berbasis Web Di Telaga 1". Penelitian ini mengimplementasikan Gammu pada sistem pemesanan lapangan futsal berbasis 
web sehingga menghasilkan web bagi Telaga 1 . Sistem yang dibangun memiliki 4 aktor yaitu: masyarakat umum, member, operator, pimpinan. Di Telaga 1 sendiri dalam pencatatan pemesanan maupun pembayaran masih menggunakan cara pesan manual dengan menggunakan kertas yang dijadwal secara manual dengan membuat tabel-tabel yang berisi tentang jadwal pemesanan setiap bulannya. Sistem dibangun menggunakan framework CodeIgneter dan database MySQL untuk mempermudah dalam penyimpanan data. Untuk pemberitahuan yang dilakukan melalui SMS maka penggunaan SMS Gateway dapat menjadi solusi. SMS Gateway dapat digunakan untuk komunikasi dua arah, mengirim dan menerima pesan, maka SMS Gateway cocok digunakan sebagai SMS Center di Telaga 1 Seturan Sleman untuk meningkatkan kualitas komunikasi. Dengan digunakannya Gammu dalam penelitian ini fungsi dari Gammu sebagai alat penghubung atau menjembatani antara modem dengan komputer, untuk memantau kapan modem mengirim SMS ke member.

3. Menurut Afrina dan Ibrahim (2015) dalam jurnal "Pengembangan Sistem Informasi SMS Gateway Dalam Meningkatkan Layanan Komunikasi Sekitar Akademika Fakultas Ilmu Komputer Unsri'. Penelitian ini dilakukan oleh peneliti yang akan memberikan akses control sesuai dengan kebutuhan user seperti dekan dapat memberikan disposisi langsung kepada pembantu dekan. Kabag dan kasubag juga dapat memberikan disposisi dengan karyawan lainnya. Begitu juga dengan ketua jurusan dapat memberikan disposisi ke sekretaris jurusan atau ke semua dosen. Sehingga sistem yang akan dikembangkan memberikan kemudahan laju pencapai tujuan secara global sedangkan secara khusus penggunaan sistem ini membantu penyampaian disposisi yang sekaligus bisa berisi perintah kerja maupun informasi tersampaikan secara real time. Pemilihan teknologi SMS Gateway pada penelitian ini dikarenakan keluasan jangkauan sinyal dari smartphone yang sudah menjadi kecenderungan dimiliki setiap orang.

4. Menurut Wijaya dan Suhartini (2016) dalam jurnal "Sistem Informasi Perubahan Harga Komoditi Menggunakan Algoritma C4.5 Dengan Sms Gateway". Penelitian ini dilakukan pada Disperindagsar berkaitan erat dengan proses monitoring data harga komoditi yaitu memberikan informasi terhadap instansi. Namun lambatnya Laporan dari surveyor lapangan membuat informasi menjadi terhambat. Sebuah sistem informasi diperlukan untuk memudahkan surveyor dalam memberikan laporan data harga dengan format SMS Gateway. Algoritma C4.5 digunakan untuk menentukan parameter entropy terdiri dari harga kemarin dan harga sekarang sedangkan gain parameter terdiri dari turun, tetap dan naik, yang tujuannya untuk membangun pohon keputusan serta untuk memilih atribut sebagai akar, didasarkan pada nilai gain tertinggi dari atribut-atribut yang ada. Hasil yang diperoleh dari penelitian ini adalah sebuah sistem SMS Gateway 
menggunakan Gammu sebagai media informasi perubahan harga komoditi hari kemarin dan harga komoditi hari ini.

5. Menurut Ningsih (2016) dalam laporan "Sistem Informasi Rute Jalur Bus Beserta Tarif Berbasis Sms Service dengan Gammu Sms Gateway pada Batik Solo Trans (BST)", Penelitian ini dilakukan untuk mengembangkan pelayanan Batik Solo Trans (BST) kepada masyarakat dengan meningkatkan informasi melalui jalur Batik Solo Trans (BST) yang di cakup dengan sistem sms gateway. Sms gateway digunakan sebagai penghubung antara telepon genggam dan komputer untuk mengirim informasi secara efisien dan efektif. Sms gateway akan melakukan semua proses dan koneksi serta menyediakan interface yang mudah dan standar. Sehingga dengan adanya sistem informasi menggunakan sms gateway ini diharapkan dapat mempermudah penumpang mengetahui tentang jalur yang di lewati BST dan dapat meningkatkan kesadaran masyarakat untuk naik angkutan umum. Penelitian yang dilakukan tidak hanya mencakup SMS Gateway tetapi website yang menggunakan system informasi geografis, dimana system informasi geografis memberikan informasi melalui maps yang langsung di koneksikan dengan google maps.

6. Menurut Imroatul, dkk (2017) dalam jurnal "Pembuatan Modul SMS Request pada Aplikasi Akademik Politeknik Telkom Berbasis Gammu", dimana Politeknik Telkom merupakan salah satu perguruan tinggi di Bandung yang memanfaatkan ICT di lingkungan akademiknya, terutama unit sistem informasi kampus yang bertugas memberikan layanan informasi akademik kepada mahasiswa dan civitas akademika lain seperti orang tua mahasiswa. Namun, terdapat kendala dalam penyampaian informasi tersebut kepada mahasiswa dan orang tua mahasiswa. Kendala yang muncul yaitu proses pemberitahuan dengan surat membutuhkan waktu yang lama serta alamat orang tua terkadang berubah sehingga surat tidak tersampaikan dengan benar. Hal tersebut membuat penyampaian informasi akademik mahasiswa ke orang tua menjadi tidak efektif. Sehingga perlu dirancang suatu aplikasi untuk mengakses informasi akademik mahasiswa dengan menggunakan media SMS agar dapat mempermudah, mempercepat, sekaligus menghemat biaya dalam melakukan pengaksesan informasi akademik yang dibutuhkan oleh mahasiswa dan orang tua mahasiswa Politeknik Telkom. Mengingat layanan SMS sebagai salah satu layanan seluler yang paling populer saat ini sangat diminati masyarakat karena penggunaannya yang relatif mudah serta biaya yang sangat murah dibanding dengan biaya telepon. Sistem yang dibuat adalah aplikasi SMS Gateway berbasis GAMMU dan menggunakan MySQL sebagai databasenya. Metode pengembangannya menggunakan SDLC dengan model waterfall. Pada aplikasi ini terdapat fungsionalitas yang memudahkan 


\section{HASIL DAN PEMBAHASAN}

\subsection{Analisa Permasalahan}

Setelah mengamati dan meneliti dari beberapa permasalahan yang terjadi pada sistem yang berjalan, terdapat beberapa alternatif pemecahan dari masalah yang dihadapi, antara lain :

1. Diperlukan aplikasi pesan pengingat komponen masuk karena mobilitas planner yang tinggi.

2. Diperlukan efisiensi pengguanaan kertas tanpa harus menumpuk di meja kerja, cukup hanya dalam bentuk display pada handphone

3. Adanya sistem yang dapat digunakan dimana saja, kapan saja dan tidak memakan waktu lama.

\begin{tabular}{|l|l|l|}
\hline No & \multicolumn{1}{|c|}{ Sistem berjalan } & \multicolumn{1}{c|}{ Sistem us ulan } \\
\hline 1. & Data Masuk komponen & Data masuk komponen disampaikan \\
& hanya di tulis di Excel & tercetak di Excel \\
\hline 2. & diantar secara manual ke & Data Delivery note hanya berupa \\
& meja Planner & informasi via SMS \\
\hline
\end{tabular}

Tabel 1. Analisa permasalahan sistem berjalan dengan sistem usulan

\subsection{Pemecahan Masalah}

Dalam melakukan pemecahan masalah, penulis juga menggunakan Use case diagram yang menggambarkan fungsionalitas yang diharapkan dari sebuah sistem. Yang ditekankan adalah "apa" yang diperbuat sistem, bukan "bagaimana" sebuah sistem bekerja. Sebuah Use case mempresentasikan sebuah interaksi antara actor dengan sistem. Berikut ini merupakan rancangan use case diagram yang dibuat : 


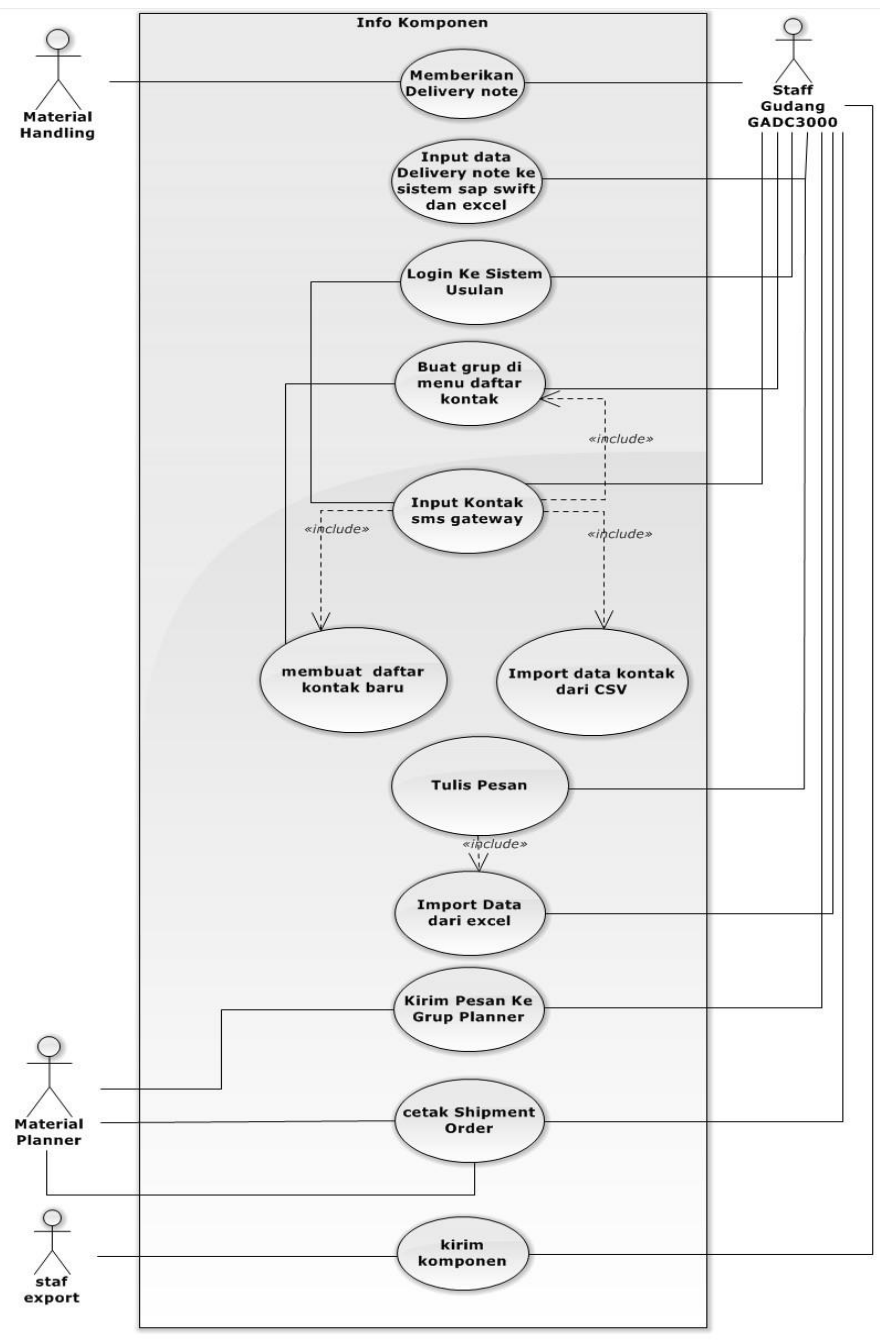

Gambar 1. Use case Diagram yang diusulkan

Berdasaran gambar 1 Use case Diagram yang diusulkan terdapat:

1. 1 Terdapat 3 actor yaitu : Planner, Material Handling, dan Staf Gudang GADC 3000 .

2. Terdapat 8 Use case yaitu: 1Use case dilakukan oleh Material Handling yaitu memberikan nilai ke Staf Gudang GADC 3000, 6 usecase dilakukan oleh Staf Gudang GADC 3000 yaitu input nilai dari Material Handling dengan ms.excel, login kesistem usulan, buat grup di menu daftar kontak, input kontak,tulis pesan, kirim pesan ke grup..

3. Terdapat 3extend yaitu extend dari use input kontak ke Use case tulis pesan yaitu melalui form kontak, import dari CSV, dan input data part number dan serial number dari excel., input kontak,tulis pesan, kirim pesan ke grup. 


\subsection{Tampilan Sistem}

\subsubsection{Tampilan menu Login}

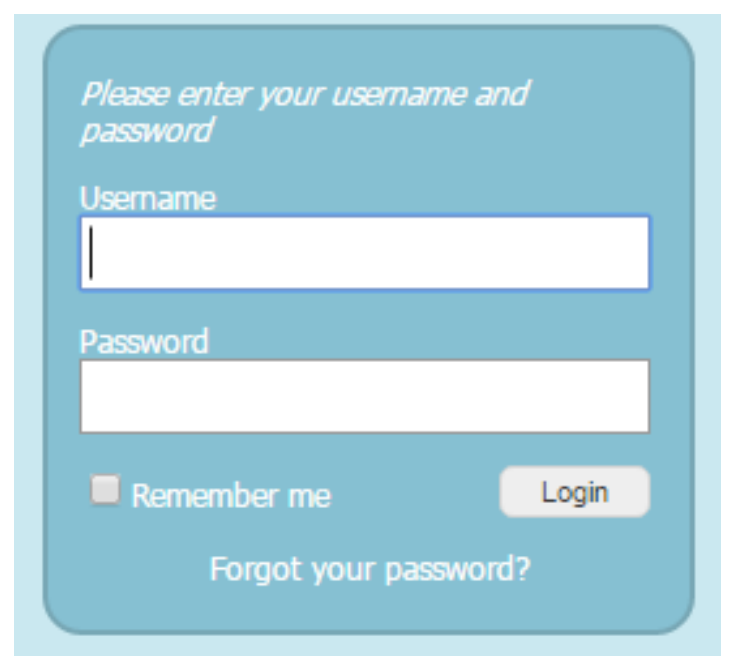

Gambar 2. Tampilan menu login

\subsubsection{Tampilan halaman awal}

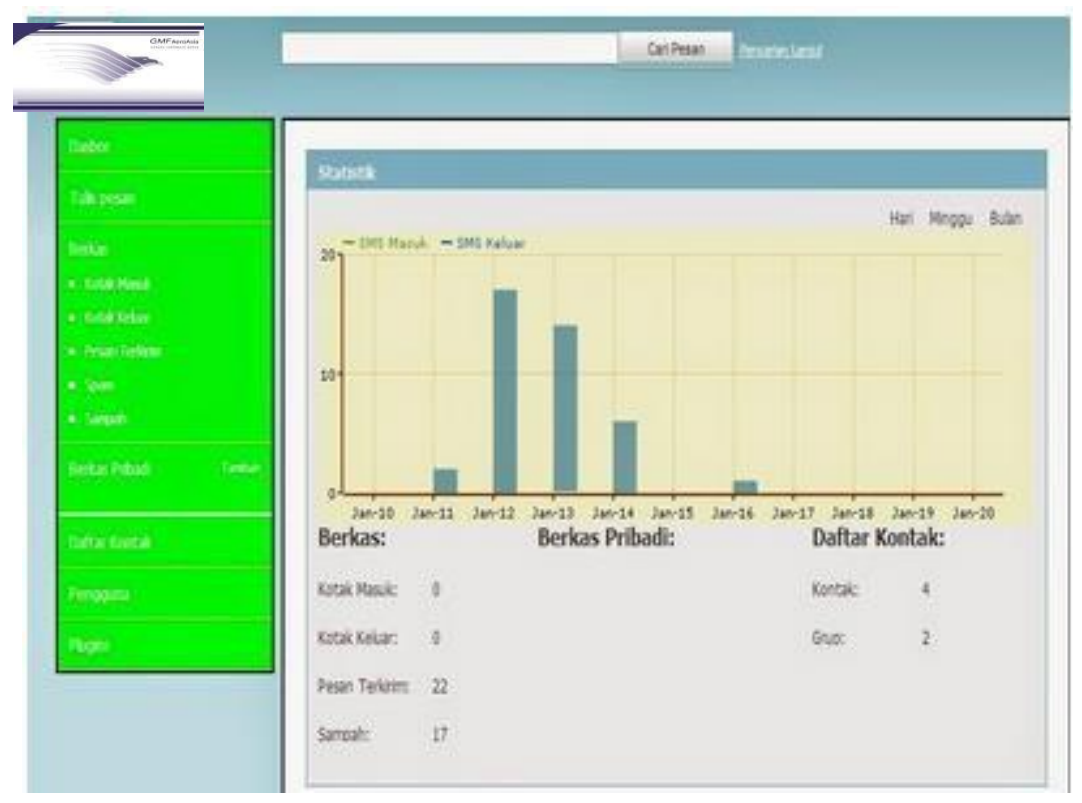

Gambar 3. Tampilan halaman awal 


\subsubsection{Tampilan menu grup}

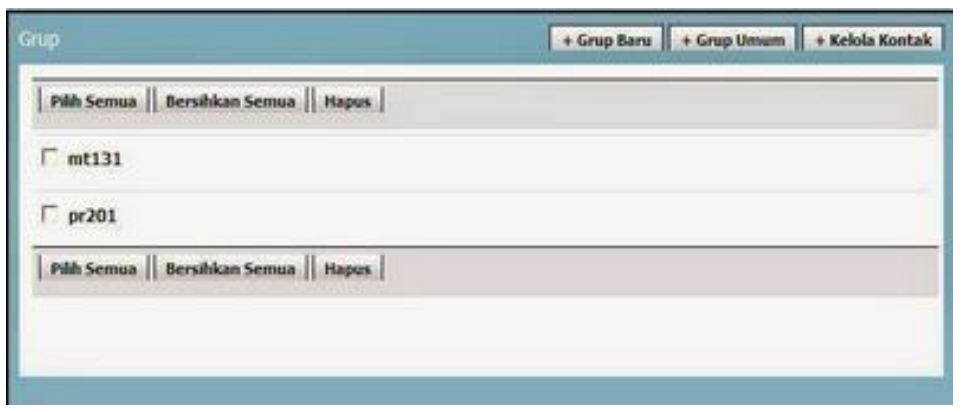

Gambar 4. Tampilan menu grup

\subsubsection{Tampilan form tambah kontak}

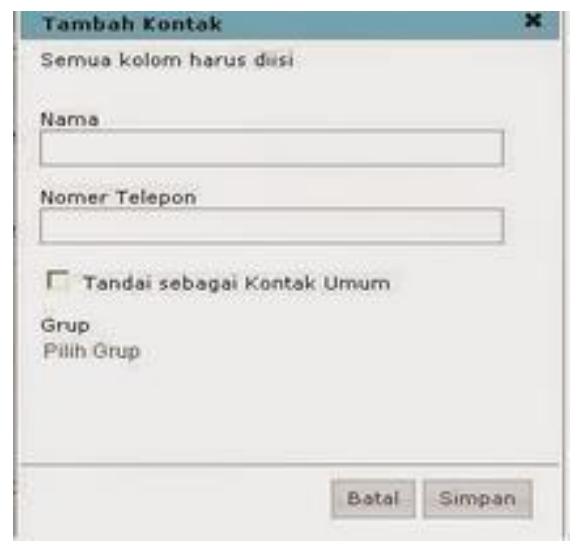

Gambar 5. Tampilan form tambah kontak

\subsubsection{Tampilan Daftar kontak}

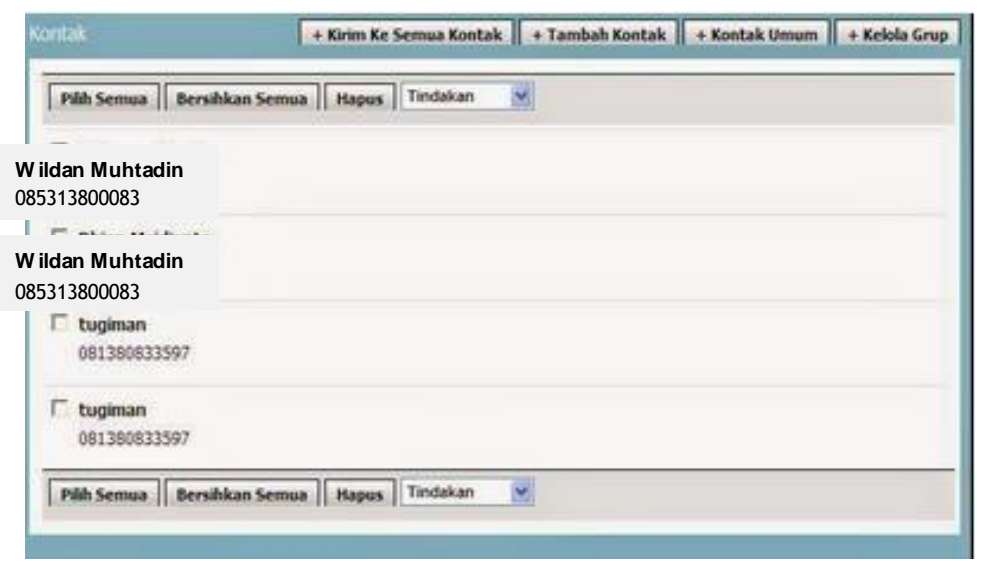

Gambar 6. Tampilan daftar kontak

127 | AlHusain, Wildan, Agus - Perancangan Sistem Informasi 


\subsubsection{Form tulis pesan}

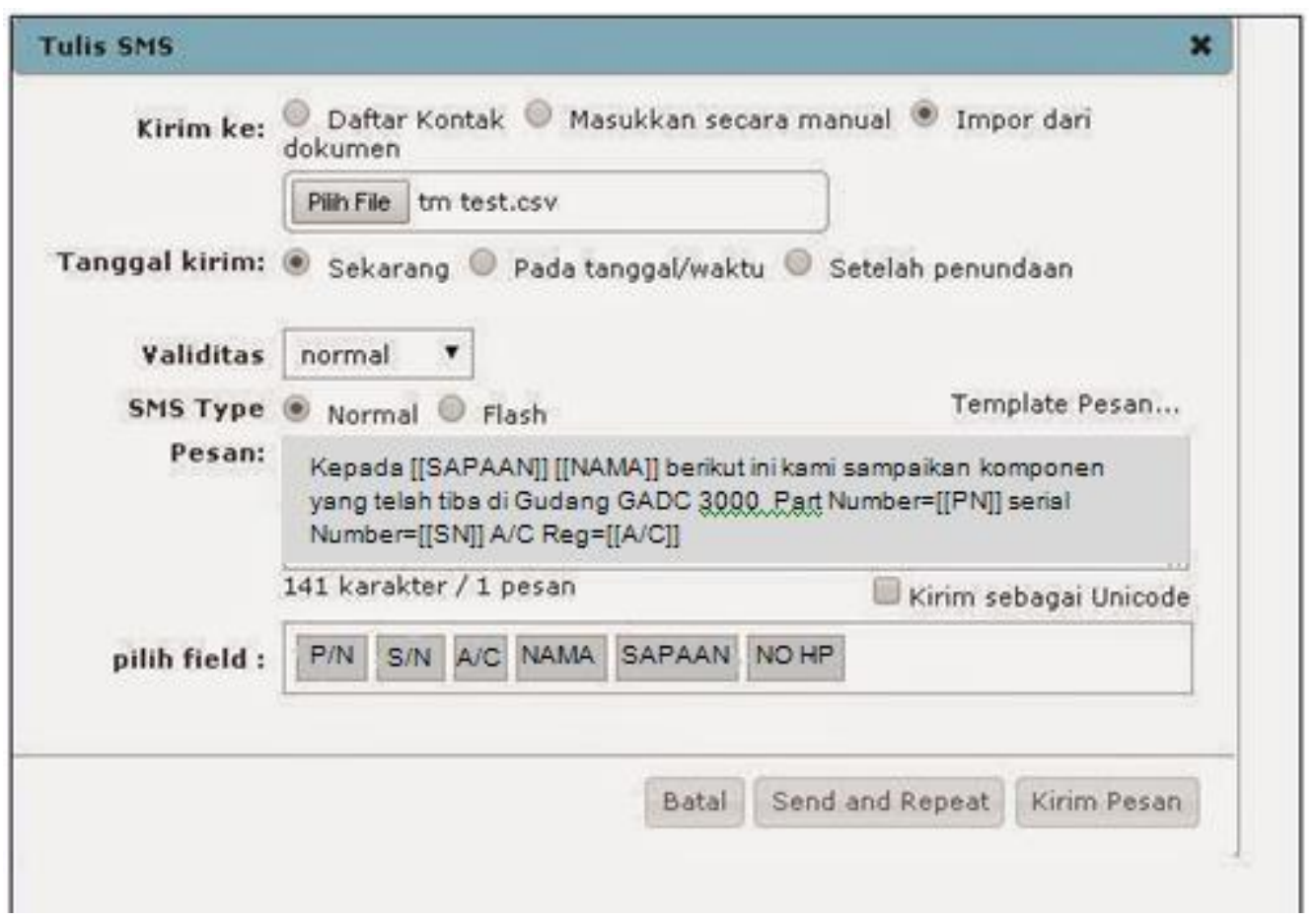

Gambar 7. form tulis pesan

\subsubsection{Tampilan pesan di ponsel}

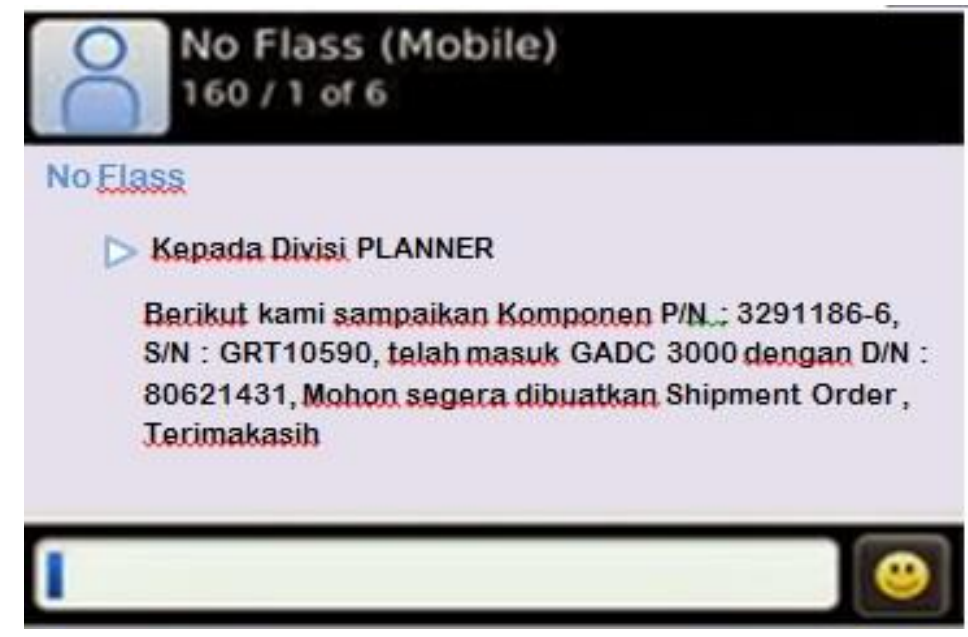

Gambar 8. Tampilan pesan di ponsel 


\subsubsection{Tampilan data pesan terkirim}

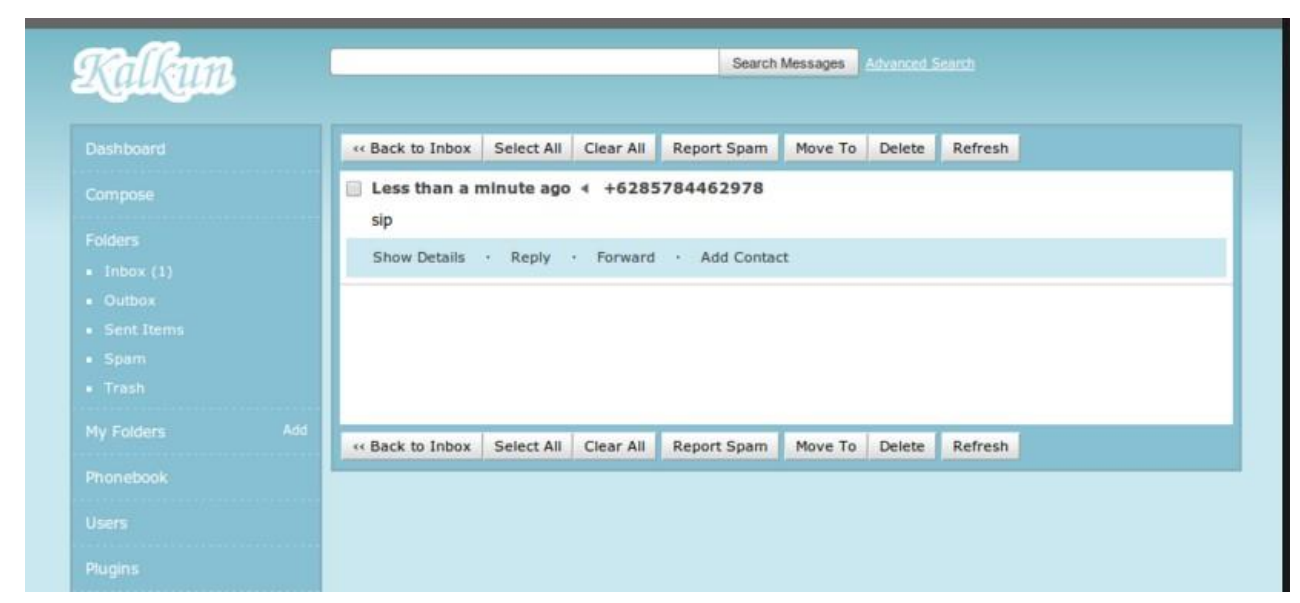

Gambar 9. Tampilan Data Pesan Terkirim

\subsubsection{Tabel data komponen yang diambil spesifikasinya}

\begin{tabular}{|l|l|l|l|l|l}
\hline PART NUMBR & $\begin{array}{l}\text { SERIAL } \\
\text { NUMBER }\end{array}$ & DESCRIPTION & $\begin{array}{l}\text { INCOMING } \\
\text { DATE }\end{array}$ & $\begin{array}{l}\text { DEUVERY } \\
\text { NOTE }\end{array}$ & REMARK \\
\hline 40176 & 23415 & Main Batery & $15-01-2016$ & 8054326 & U/S \\
\hline $77985-5$ & N7865708684 & Oven & $12-01-2016$ & 8055747 & U/S \\
\hline
\end{tabular}

Tabel 10. data komponen yang akan diambil spesifikasinya

\section{KESIMPULAN}

Berdasarkan hasil analisa terhadap perumusan masalah, maka penulis dapat menyimpulkan bahwa:

1. Penyampaian informasi komponen yang datang kepada Material Planner yang berjalan saat ini belum efektif karena informasi masih disampaikan dengan cara di lihat langsung ke gudang

2. Penyampaian informasi kedatangan komponen yang berjalan saat ini manual karena staf Gudang GADC 3000 harus membawa Delivery note ke meja Planner lalu menunggunya untuk diproses dan ditukar dengan Shipment order.

3. Untuk dapat menyampaikan informasi komponen kepada Planner maka dibuatkanlah aplikasi informasi pengingat yang dapat diakses via handphone.

\section{SARAN}

Saran yang dapat digunakan sebagai bahan pertimbangannya adalah sebagai berikut: 
1. Disarankan untuk mengembangkan sistem ini dengan menambahkan fasilitas menyimpan daftar komponen kedalam data base sehingga tidak perlu lagi menggunakan ms. Excel sebagai media pengambilan data komponen

2. Disarankan untuk membuat fasilitas yang bisa memasukan 1 no telepon ke dalam beberapa grup tanpa harus membuat no telpon ganda di daftar kontak.

3. Disarankan untuk mengunakan aplikasi ini agar staf Gudang GADC 3000 tidah perlu mengantar Delivery note ke meja Planner yang membutuhkan waktu tambahan. Dan Planner akan segera membuatkan Shipment order karena sudah mengetahuilebih awal keberadaan komponen tersebut.

\section{DAFTAR PUSTAKA}

[1] Kermite, R. Y., Winarno, A., Kom, M., Rohmani, A., \& Kom, M. (2017). Perancangan Sistem Administrasi Sekolah Dengan SMS Gateway Berbasis Web Menggunakan Gammu Pada SMK LPI Semarang. Skripsi Sistem Informasi UDINUS.

[2] Nugroho, A. (2018). IMPLEMENTASI GAMMU PADA SISTEM PEMESANAN LAPANGAN FUTSAL BERBASIS WEB DI TELAGA 1 (Doctoral dissertation, STMIK AKAKOM YOGYAKARTA).

[3] Afrina, M., \& Ibrahim, A. (2015). Pengembangan Sistem Informasi SMS Gateway Dalam Meningkatkan Layanan Komunikasi Sekitar Akademika Fakultas Ilmu Komputer Unsri. Jurnal Sistem Informasi, 7(2).

[4] Wijaya, A. E., \& Suhartini, I. (2016). SISTEM INFORMASI PERUBAHAN HARGA KOMODITI MENGGUNAKAN ALGORITMA C4. 5 DENGAN SMS GATEWAY (Studi Kasus Disperindagsar Kab. Subang). SEMNASTEKNOMEDIA ONLINE, 4(1), 1-3.

[5] Ningsih, E. W. (2016). Sistem Informasi Rute Jalur Bus Beserta Tarif Berbasis Sms Service dengan Gammu Sms Gateway pada Batik Solo Trans (BST) (Doctoral dissertation, Universitas Muhammadiyah Surakarta).

[6] Izzah, I. K., Fahrudin, T., \& Putro, B. L. (2017). Pembuatan Modul SMS Request pada Aplikasi Akademik Politeknik Telkom Berbasis Gammu. Konferensi Nasional ICT-M Politeknik Telkom. 